\title{
Online Homework in Engineering Mathematics: Can We Narrow the Performance Gap?
}

\author{
https://doi.org/10.3991/ijep.v8i1.7526 \\ Mikko Vasko( $\left.{ }^{\square}\right)$, Stefan Ritter, Gottfried Metzger \\ Karlsruhe University of Applied Sciences, Karlsruhe, Germany \\ mikko.vasko@hs-karlsruhe.de
}

\begin{abstract}
In this study we examine the introduction of online homework in a first-semester engineering mathematics course at a German university of applied sciences. The aim of the study was to find out whether students in general and students with low incoming mathematics skills in particular benefit from graded online homework. We found a high correlation between the number of online homework problems correctly solved and exam results, but also between initial placement test scores and exam results. Furthermore, we found that students with high placement test scores were more likely to use online homework regularly. We conclude that although online homework can promote successful student learning, further efforts are necessary to ensure completion of homework especially by students with low placement test scores.
\end{abstract}

Keywords - computer aided learning; didactics (pedagogy) of higher education; engineering education; mathematics education

\section{Introduction}

Many engineering students at German universities of applied sciences (Hochschule für Angewandte Wissenschaften) cannot progress in their engineering studies because they cannot pass the required mathematics courses [1, p. 158]. One reason for failing these courses is that many students begin their studies with insufficient skills in mathematics [2], [3]. Kurz et al. [4] report a strong correlation between these incoming mathematics skills and the final grade point average of engineering students graduating with a bachelor's degree from a university of applied sciences in Germany. Engineering education would be all the more effective, were we able to narrow this performance gap in mathematics.

Traditionally, mathematics courses in German universities of applied sciences include a significant part of self-study. Practice has typically taken the form of voluntary homework, since the professors have a high teaching load and academic staff is rarely available for grading homework. However, many students tend to ignore voluntary homework until shortly before the final exam [5]. Only high-achieving students are likely to invest time on self-study early in the semester [6, p. 265]. In fact, research on homework indicates that in order to be accepted by students and to be effec- 
tive, homework should be graded [7, p. 217], [8, p. 2]. Automatically assessed and randomized online homework could provide a solution to this issue.

Online homework can also include immediate feedback as well as the possibility to fix errors based on that feedback, both of which have been shown to improve learning [9], [10, p. 62]. Moreover, Walberg et al. [11] reported that homework without feedback had only a small effect on student learning, a point also stressed by Hattie [12], [13].

In this study we designed an online homework intervention especially to benefit all students, but those with low incoming mathematics skills in particular. The intervention was designed in a way that as many students as possible would actually complete the online homework assignments, and that the use of online homework would be beneficial for the learning of all students. Using the insight of van Gog et al. [14, p. 75] our design captured aspects of deliberate practice i.e. "an appropriate, challenging level of difficulty, and enable successive refinement by allowing for repetition, giving room to make and correct errors, and providing informative feedback to the learner".

\section{The Research Questions}

Our specific research questions were the following:

1. What effect does online homework have on students' exam performance in a first semester engineering mathematics course? How large is the effect?

2. How far is the effect moderated by the incoming mathematics skills of the students?

3. To which extent is online homework accepted by students? Which factors influence the acceptance? By acceptance we refer to regular use as well as the students' opinions on online homework.

\section{Review of Research}

Previous research comparing the use of paper-based homework to online homework has typically reported no significant difference in student learning [15]-[18]. The studies conclude that the homework medium was not a deciding factor for student performance. However, Babaali and Gonzales [19] showed that where additional online homework with immediate feedback was provided, those students completing the online problems performed better in the final exam.

Previous research also indicates that students are more motivated to complete online homework than paper-based homework [20]. Furthermore, several studies on the acceptance of online homework have shown that students appreciate online homework in mathematics courses [9, p. 2], [17], [21]-[23].

The effects of online homework on students with different incoming mathematics skills have been studied by Mathai and Olsen [18], Brewer and Becker [16] and Macnab et al. [24]. Whereas Mathai and Olsen [18] report that only students with high incoming skills benefited from online homework, Brewer and Becker [16] reported 
contrary results. In fact, Brewer and Becker found that while high-skilled students benefited equally from online and paper-based homework, low-skilled students showed significantly higher mathematical achievement when completing online homework as compared to paper-based homework. Macnab et al. [24] also report that students with average or low incoming skills benefited from computer based drill and practice, which was conducted in pairs in a computer pool.

\section{Methods}

We implemented online homework in a first year engineering mathematics course (Höhere Mathematik 1) attended by students in the degree programs Information Technology and Industrial Automation. The course includes 14 weeks of lectures with $3 \times 90$ minutes per week as well as voluntary weekly exercises held by undergraduate teaching assistants. The students receive 6 ECTS for passing the final exam. The topics covered in the course include complex numbers, matrices, systems of linear equations, vector algebra, analytic geometry and elementary functions. The learning objects were first, to master mathematical procedures needed in the following engineering courses, and second, to improve the skills in problem solving and mathematical thinking. The group size varied between 30 and 50 students. The lectures included a presentation by the teacher, as well as active learning methods, such as problem solving in small groups or individually, and discussions. According to the syllabus the course included approximately 90 hours of self-study. The study materials consisted of lecture notes, worked examples, old exams, and video material. Prior to the introduction of online homework self-study was neither graded nor controlled.

The students were given four online homework assignments, the students having three weeks to complete each assignment. Each assignment included 16 to 22 mathematical problems, in total 79 problems. The students were expected to solve the problems on paper and then enter their answers into the online homework system. The assignments were created with progressive difficulty, starting with easy drill and practice and proceeding to more complicated exam-level problems. We did not use multiple choice questions, since these are not suitable for university level mathematics [25, pp. 2-4]. Instead all problems in the assignments were 'open' and required students to enter their answers in mathematical syntax similar to that used in scientific calculators. The problems were randomized, so that each student had a different but similar assignment.

The students received immediate feedback whether their answer was correct or incorrect and had unlimited number of tries on each problem. Students who were unable to solve a problem were encouraged to seek help of the teacher, the tutors, or fellow students. Students, who correctly solved more than $80 \%$ of the problems in at least three assignments, received $10 \%$ improvement to the final grade, but only if they had passed the final exam. Thus, online homework helped the students to get a better final grade, but did not contribute to passing the exam. Midterm exams were not offered. Thus the final grade consisted of the final exam (90\%) and online homework (10\%). 
The effects of online homework were studied in four subsequent cohorts. All four cohorts were taught by the same teacher, and the same online homework assignments were used in each semester. In addition, the course set-up, topics, teaching methods and the study materials remained constant throughout these four semesters. Repeating students were excluded from the study, since our main interest was to support passing the exam at the first attempt.

Two different online homework systems specifically designed for mathematics homework were used. The first three cohorts used Maple T.A. ${ }^{\text {TM }}$ (MapleSoft ${ }^{\mathrm{TM}}$ ). The fourth cohort used the open source system STACK developed by Chris Sangwin at the University of Birmingham, UK. STACK is a plug-in for the open source learning management systems Moodle and ILIAS. From students' perspective both systems, Maple T.A. ${ }^{\text {TM }}$ and STACK, offer the same features. Both systems use a computer algebra system in the background, which enables intelligent randomization of questions, as well as correct evaluation of mathematical expressions provided by students.

To be able to compare the effects of online homework on students with different incoming mathematics skills, we tested the students at the beginning of their first university semester. This voluntary paper-and-pencil mathematics placement test included 24 multiple choice questions covering school mathematics. The test is similar to the test used by Kurz et al. [4]. The test results were reported back to the students with the aim of creating awareness of the students' level of mathematical knowledge. Only students who took part in the mathematics placement test were included into the study.

The students' opinions on online homework were asked at the end of the semester with a questionnaire consisting of both Likert scale and open ended questions.

\section{The Data}

\subsection{Mathematics Placement Test Score}

In the mathematics placement test the 119 participating students reached test scores between 4 and $24(M=14.03, S D=4.59, M d n=14$, see Figure 1). The sample consists of $76 \%$ of all students in the four cohorts. 


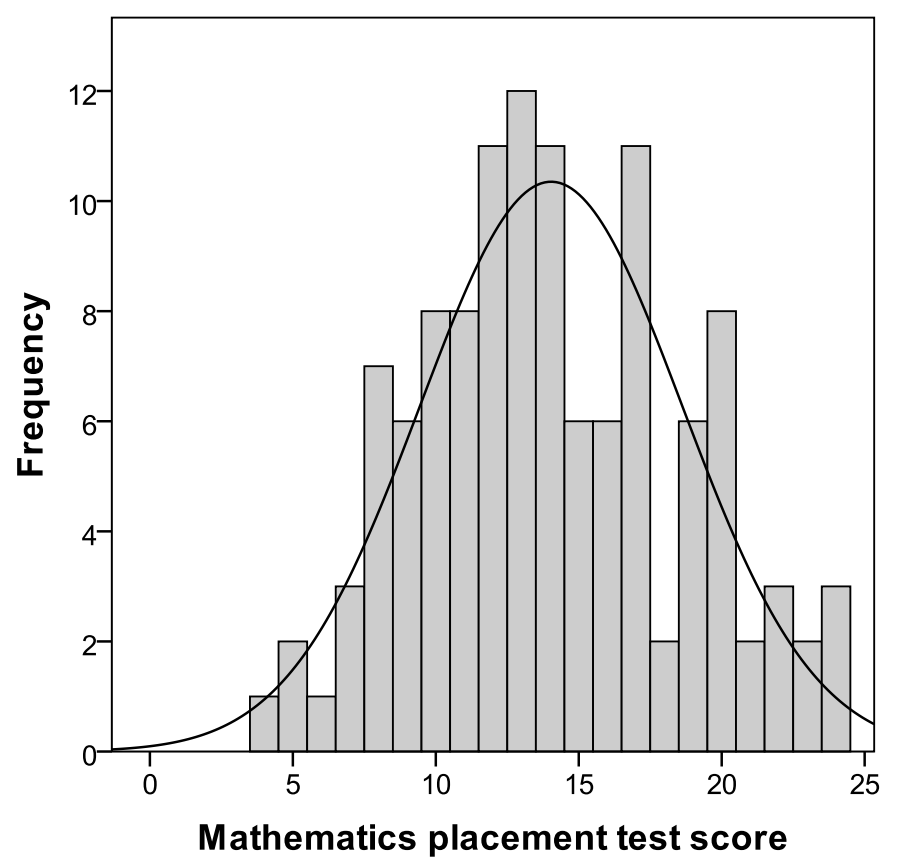

Fig. 1. The distribution of the mathematics placement test scores

There were only small differences in the mean test scores between the four cohorts (see Table 1) and the differences did not reach statistical significance, $F(3,115)=$ $0.999, p=.396$ (An alpha level of .05 was used for all statistical tests.), which may be explained to some degree by the small sample sizes.

Table 1. Mathematics placement test scores by cohort

\begin{tabular}{l|ccccc}
\multicolumn{1}{c|}{ Cohort } & n & M & SD & Min score & Max score \\
\hline Winter 2013/2014 & 31 & 13.32 & 4.42 & 4 & 22 \\
Summer 2014 & 22 & 13.09 & 4.87 & 7 & 24 \\
Winter 2014/2015 & 32 & 14.72 & 4.45 & 5 & 24 \\
Summer 2015 & 34 & 14.65 & 4.68 & 8 & 24 \\
\hline Total & 119 & 14.03 & 4.59 & 4 & 24
\end{tabular}

For some of the following analyses the sample was divided into three almost equally sized groups based on the mathematics placement test score:

- High incoming mathematics skills (score 16-24 in the placement test, $n=43$ )

- Average incoming mathematics skills (score 12-15 in the placement test, $n=40$ )

- Low incoming mathematics skills (score 0-11 in the placement test, $n=36$ ) 


\subsection{Number of Online Homework Problems Solved}

The students had unlimited number of tries on each problem and were allowed to use all tools they needed to solve the online homework problems. Thus, the number of online homework problems solved by a student does not per se represent the student's level of mathematical knowledge. We interpret the number of problems solved as a level for the dose of the intervention, i.e. the intensity at which a student used the online homework system.

The students in the sample solved up to 76 mathematical problems in the online system $(M=50.36, S D=20.18, M d n=55)$. The number of problems solved was not normally distributed (see Figure 2); therefore we decided to use non-parametrical analyses for this variable and dichotomized this variable for inclusion into a multiple regression analysis. Hence, the students solving 40 or less problems were assigned to one group $(M=17.29, S D=12.12, M d n=20, \mathrm{n}=27)$ and the students solving more than 40 problems to the other group $(M=60.05, S D=8.16, M d n=69, n=92)$. A Kruskal-Wallis $\mathrm{H}$ test showed no significant differences in the number of problems solved between the four cohorts, $\left.\chi^{2}(3)=5.205, p=.157\right)$.

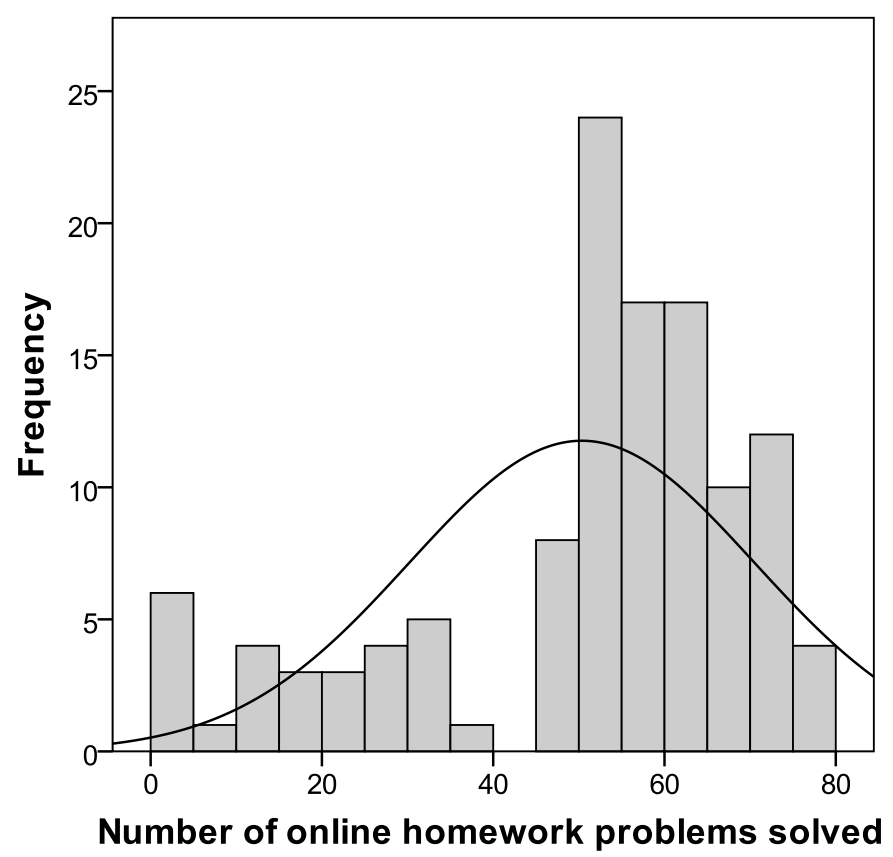

Fig. 2. Distribution of the number of online homework problems solved 


\subsection{Exam Score}

In total $53 \%$ of the students in all four cohorts passed and $47 \%$ failed the exam. Taken separately, the success rate of the four cohorts ranged from $36 \%$ to $65 \%$ (see Table 2).

Table 2. Mathematics placement test scores by cohort

\begin{tabular}{l|ccc}
\multicolumn{1}{c|}{ Cohort } & n & \% pass & \% fail \\
\hline Winter 2013/2014 & 31 & $65 \%$ & $35 \%$ \\
Summer 2014 & 22 & $36 \%$ & $64 \%$ \\
Winter 2014/2015 & 32 & $56 \%$ & $44 \%$ \\
Summer 2015 & 34 & $50 \%$ & $50 \%$
\end{tabular}

Considering this high variation in the exam success rates and the relatively low variation in the mathematics placement test scores between the four cohorts (see above) we could not conclude the exam difficulty being constant. Therefore we standardized the exam score within each cohort and used the z-value for the analyses (see Figure 3). We also repeated our analyses with different variants of this success criterion (e.g. percentage of tasks solved) and all led to similar results.

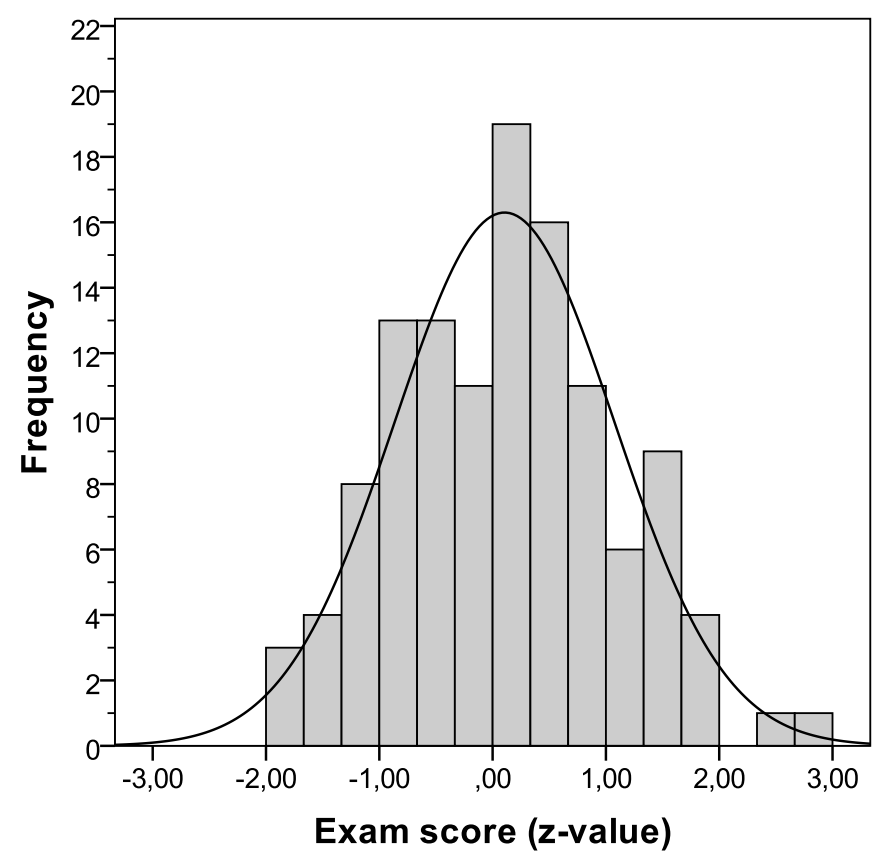

Fig. 3. Distribution of the exam scores 


\section{The Results}

\subsection{Effect of Online Homework on Exam Performance}

At first we studied what effect online homework has on students' exam performance and how large this effect is. Students passing the exam had solved more online homework problems during the semester $(M d n=61, \mathrm{n}=63)$ than students failing the exam $(M d n=49, n=56$, see Figure 4). A Mann-Whitney U-Test for independent samples indicated a significant difference between the two groups, $U=-5,487, p<$ .001 .

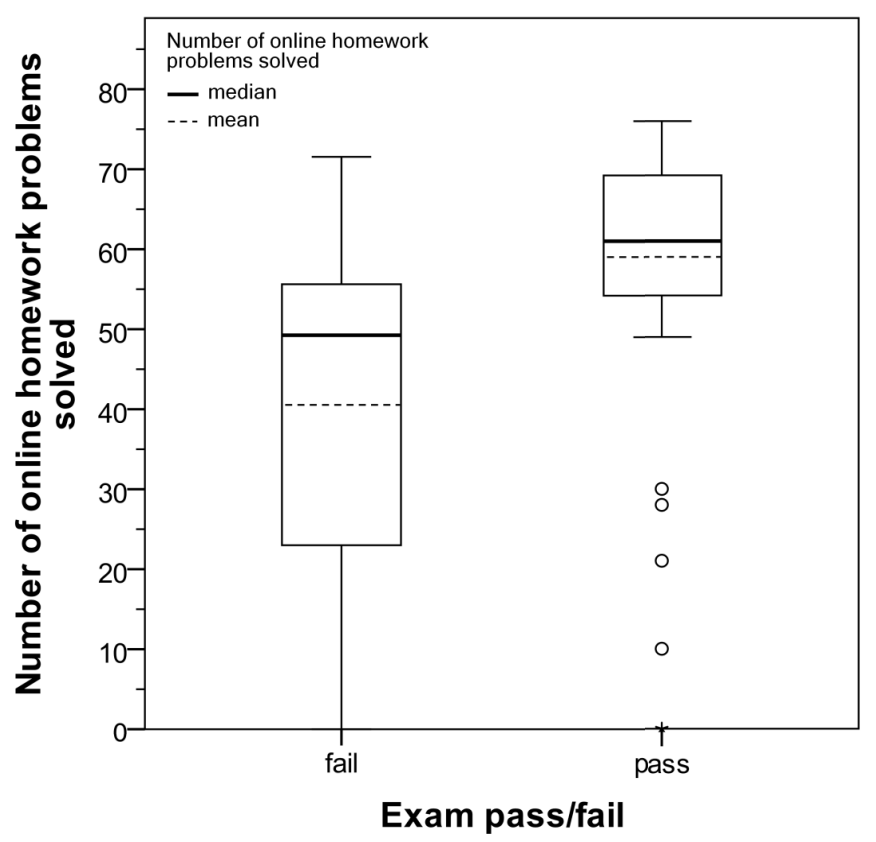

Fig. 4. Comparison of the number of online homework problems solved between students who passed or failed the exam.

The number of online homework problems solved and the exam score were strongly positively correlated, $r_{s}(119)=.62, p<.001$. The higher the intensity of use of online homework during the semester the higher the exam score at the end of the semester.

To examine the relation between the dichotomized usage of the online-homework and whether or not passing the exam, a chi-square test of independence was conducted. There was a significant relationship between these two variables, $\chi^{2}(1, N=119)=$ $16.61, p<.001$. Students not using the online homework were more likely to fail the exam; $81.5 \%$ of those students not using the online homework on a regular basis $(n=$ 27 ) failed the exam, but only $37 \%$ of the regular users $(n=92)$. 


\subsection{Influence of Incoming Mathematics Skills}

In the next step, we wanted to know, how far is the effect of online homework on exam performance moderated by the incoming mathematics skills of students. The mathematics placement test score and the exam score (z-value) were strongly positively correlated, $r_{s}=.54, p<.001$. The higher the score achieved in the mathematics placement test at the beginning of the semester, the better was the result in the exam at the end of the semester.

The mathematics placement test score and the number of online homework problems solved during the semester were also positively correlated, $r_{s}(119)=.36, p<$ .001 . Regarding the intensity of use within the three groups segmented by the placement test score, $91 \%$ of the students with a high mathematics placement test score (16-24) but only $56 \%$ of those with a low test score (0-11) used the online homework regularly.

Students with high mathematics placement test scores tend to use the online homework more regularly and also tend to get better scores in the exam (Figure 5). Having low incoming mathematics skills and, at the same time, not using online homework on a regular basis go hand in hand with low exam scores and high probability of failure in the exam.

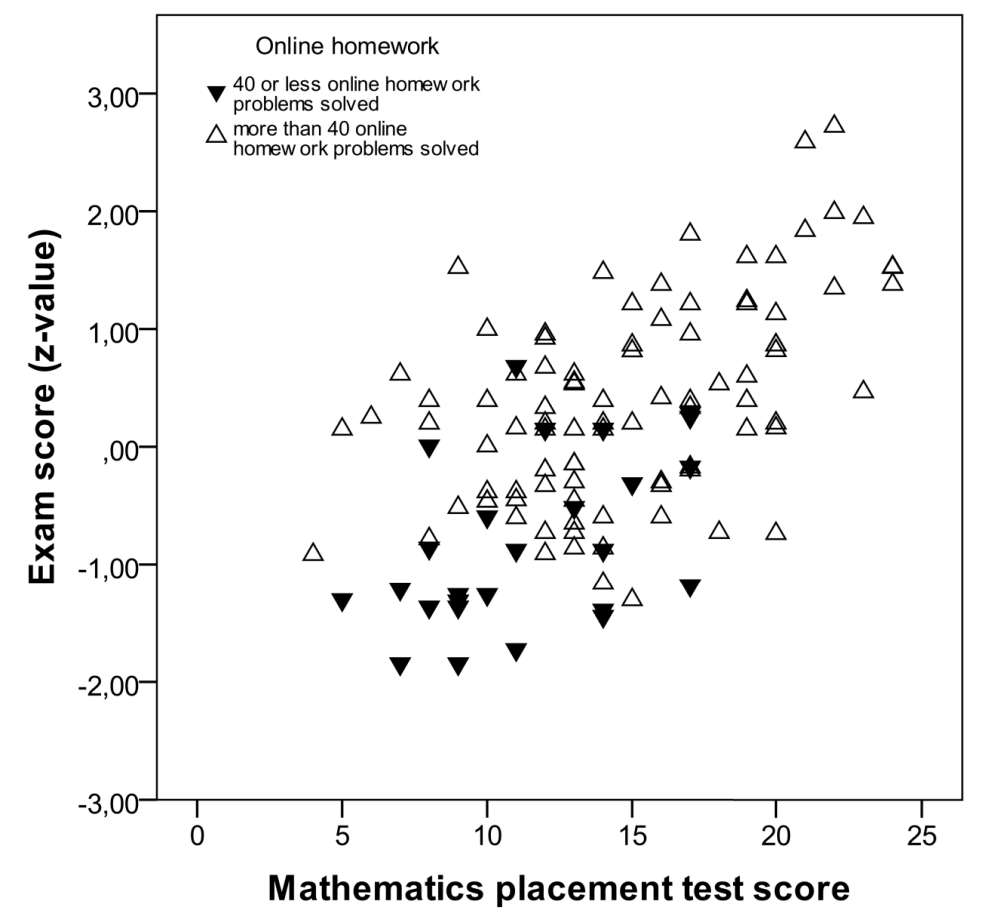

Fig. 5. The exam scores compared to the mathematics placement test scores. 
To examine the influence of both variables on the exam score at once, we used hierarchical multiple regression analysis. As mentioned above, due to the distribution of the number of problems solved during the semester, we dichotomized the intensity of use, coding disuse or irregular use of online homework as 0 and regular usage as 1 . The exam score (z-value) was used as a criterion. In a hierarchical approach the mathematics placement test score first taken into account explained $34 \%$ of the variance of the exam score $\left(R^{2}=.34, F(1,117)=60.938, p<.001\right)$. Entering the dummy coded intensity of use of online homework significantly increased the amount of variance explained. It explained additional $12 \%$ of the variation in the exam score $\left(R^{2}=.12\right.$, $F(1,116)=25.388, p<.001)$. Taken together, the two predictors explained $46 \%$ of the variance of the exam score $\left(R^{2}=.46, F(2,116)=49.514, p<.001\right)$. The mathematical placement test score $(\beta=.465, p<.001)$ and the use of the online homework $(\beta=$ $.364, p<.001)$ each significantly predicted the exam score. Holding constant the incoming skill level, regular use of the online homework during the semester, compared to disuse or irregular use, was associated with an exam score improved by 0.84 standard deviations.

\subsection{Acceptance of Online Homework}

We also studied, to which extent the students accepted the online homework and which factors influenced the acceptance. Students had to solve $80 \%$ of the problems in three assignments to receive a $10 \%$ improvement to the final grade. The improvement did not help the students to pass the exam, but was added only after a student had passed the exam. On average $76 \%$ of the students of the sample $(N=119)$ completed the online homework and received the $10 \%$ improvement to the final grade. The participation remained almost constant from semester to semester. However, we observed large differences in participation rates between students with high and students with low incoming mathematics skills (see also above). Students with high or average incoming skills were more likely to complete the homework than students with low incoming skills (Table 3).

Table 3. Completion of online homework and exam success for different incoming mathematics skill levels

\begin{tabular}{lcc}
\hline \multicolumn{1}{c}{$\begin{array}{c}\text { Mathematics } \\
\text { placement test score }\end{array}$} & n & $\begin{array}{c}\text { \% of students who successfully completed } \\
\text { the online homework }\end{array}$ \\
\hline High (16-24) & 43 & $86 \%$ \\
Average (12-15) & 40 & $83 \%$ \\
Low (0-11) & 36 & $56 \%$ \\
Total & 119 & $76 \%$ \\
\hline
\end{tabular}

A part of our sample was included in a survey on the online homework $(n=67)$. When asking the students whether they would complete the online homework without the improvement in the final grade, $48 \%$ answered no, $40 \%$ yes, and $12 \%$ could not decide. Overall the students' opinions on online homework were extremely positive. Students reported that they had positive learning experiences through the homework. 
Even when asked whether they enjoyed the homework, $67 \%$ of the students gave a positive response. In addition, $93 \%$ of the students who completed the questionnaire would like to do online homework also in the second semester mathematics course (Höhere Mathematik 2).

\section{Conclusions and Discussion}

We studied the statistical relationship between the use of online homework, the incoming mathematics skills and the exam performance, as well as the acceptance of online homework, in a first semester engineering mathematics course.

Students who were successful in the exam had used online homework more regularly than students who failed the exam. The more online homework problems a student solved throughout the semester, the better was the result in the exam. Furthermore, exam success at the end of the semester strongly positively correlated with the mathematics placement test score at the beginning of the semester. Even when simultaneously taken into account, the use of online homework and the incoming mathematics skills were both significant predictors of exam performance. But can it be concluded that the use of online homework as an intervention leads to better exam performance?

In our study, we operationalized the use of online homework on an individual level and studied the association of this variable with the exam performance. Students were not randomly assigned to different levels of intensity of use of online homework. Therefore, internal validity of our design is quite low and causal inferences are problematic. However, such a design would be very artificial, since we cannot force students to learn, but can only offer them opportunities for learning. Hence, we cannot consider online homework (or any other intervention) as a treatment for 'passive' students. Sincere use of the intervention is always crucial. At the very least, the number of online homework problems solved may be regarded as a proof for a student's engagement in active self-study throughout the semester. Our results show that those students, who completed active self-study, were more successful in the exam. Thus, the major challenge lies in creating framework conditions that motivate students to complete active self-study.

Even if there is some evidence that online homework is a useful tool for supporting active self-study in first semester engineering mathematics courses, we still have to point out the large correlation between incoming mathematics skill level at the beginning of the semester and exam performance at the end of the semester. Incoming mathematics skills seem to have large influence on exam performance.

There was also a high correlation between the intensity of use of online homework and the level of incoming mathematics skills. Students with high scores in the mathematics placement test more often regularly used online homework. Having high mathematics skills already at the beginning of the first semester may have facilitated better understanding of the course matter in general and thus the ability to solve the online homework problems with less effort, eventually visible in the number of homework problems solved. Furthermore, the mathematics placement test score may 
have been confounded with other variables, such as study motivation, learning experience, and metacognitive skills. A high mathematics placement test score may also be seen as a resultant of successful learning strategies in the school.

The intensity of use and the acceptance of online homework were the lowest among students with low incoming mathematics skills. However, those students with low placement test scores, who regularly used online homework, had higher chance to pass the exam. Thus we can say that online homework can help to narrow the performance gap between students, but only if the intervention is designed in a way that makes active participation probable. Especially the needs of students with low incoming skills have to be met. Not the sole offer of online homework is crucial but its didactical design. Many students require external rewards for completing active selfstudy. At the beginning of their studies some students might simply not recognize that active self-study during the semester is necessary for academic success. If the responsibility of active self-study is left entirely to the students, we create an unequal learning situation. Those students with high intrinsic motivation, good metacognitive skills, and high incoming mathematics skills are likely to succeed, whereas students with lower intrinsic motivation and lower incoming mathematics skills will be left without support.

The answers of the students to the questionnaire show that online homework can offer students positive learning experiences in mathematics. But if we have to conclude that the benefit the students get from online homework is highly dependent on their incoming mathematics skills and if students with low mathematics skills benefit the least of all, it might be necessary to think over our intervention strategy. Possible changes in the strategy, which would require further study, include changing the grading, increasing or decreasing the frequency and amount of online homework, connecting the online homework more intensively with in-class activities, as well as making online homework a mandatory prerequisite for admission to the exam. All these changes may influence the acceptance of online homework as well as the learning of students.

\section{Acknowledgment}

This work was supported in part by the German Federal Ministry of Education and Research, support codes 01PL11014 and 01PL16014.

\section{References}

[1] U. Heublein et al., Ursachen des Studienabbruchs in Bachelor- und in herkömmlichen Studiengängen. Ergebnisse einer bundesweiten Befragung von Exmatrikulierten des Studienjahres 2007/08. Hannover: HIS Hochschul-Informations-System GmbH, 2010. http://www.dzhw.eu/pdf/pub_fh/fh-201002.pdf

[2] H. Abel and B. Weber, "28 Jahre Esslinger Modell - Studienanfänger und Mathematik." in Mathematische Vor- und Brückenkurse, Konzepte und Studien zur Hochschuldidaktik und 
Lehrerbildung in Mathematik, edited by Isabell Bausch et al. Wiesbaden: Springer Fachmedien, 2014, pp. 9-19.

[3] H. Knospe, „Zehn Jahre Eingangstest Mathematik an Fachhochschulen in NordrheinWestfalen." Proceedings zum 10. Workshop Mathematik in ingenieurwissenschaftlichen Studiengängen. Mülheim an der Ruhr: Hochschule Ruhr-West, 2012, pp. 19-24.

[4] G. Kurz, M. Linsner and G. Metzger, „Studienerfolg und seine Prognose. Eine Fallstudie in Ingenieurstudiengängen der Hochschule für Angewandte Wissenschaften Esslingen." in Perspektiven angewandter Hochschuldidaktik - Studien und Erfahrungsberichte, M. Rentschler and G. Metzger, Eds. Aachen: Shaker, 2014, pp. 13-79.

[5] R. Schulmeister and C. Metzger, „Die Workload im Bachelor: Ein empirisches Forschungsprojekt." in Die Workload im Bachelor: Zeitbudget und Studierverhalten. Eine empirische Studie, R. Schulmeister and C. Metzger, Eds. Münster: Waxmann, 2011, pp. 13-128.

[6] K. Nandagopal and K.A. Ericsson, "Enhancing Students' Performance in Traditional Education: Implications from the Expert Performance Approach and Deliberate Practice." APA educational psychology handbook, Vol 1: Theories, constructs, and critical issues, K. R. Harris et al., Eds. Washington: American Psychological Association, 2012, pp. 257-293.

[7] J. Engelbrecht and A. Harding, "Combing Online and Paper Assessment in a Web-based Course In Undergraduate Mathematics.” J. of Comput. in Math. and Sci. Teaching, vol. 23, no. 3, pp. 217-231, 2004.

[8] M.L. Lunsford and M. Pendergrass, "Making Online Homework Work." PRIMUS: Problems, Resources, and Issues in Math. Undergraduate Stud., vol. 26, no. 6, 2015.

[9] D.M. Nguyen and G. Kulm, "Using Web-based Practice to Enhance Mathematics Learning and Achievement." J. of Interactive Online Learning, vol. 3, no. 3, pp. 1-16, 2005.

[10] P. Luik, "Characteristics of drills related to development of skills." J. of Comput. Assisted Learning, vol. 23, pp. 56-68, 2007. https://doi.org/10.1111/j.1365-2729.2007.00201.x

[11] H.J. Walberg, R.A. Paschal and T. Weinstein, „Homework's Powerful Effects on Learning." Educ. Leadership, vol. 42, no. 7, pp.76-79, 1985.

[12] J. Hattie, "The Power of Feedback." Review of Edu. Research, vol. 77, no. 1, pp. 81-112, 2007. https://doi.org/10.3102/003465430298487

[13] J. Hattie, Visible Learning. A Synthesis of Over 800 Meta-Analyses Relating to Achievement. London: Routledge, 2009.

[14] T. van Gog et al., "Instructional Design for Advanced Learners: Establishing Connections Between the Theoretical Frameworks of Cognitive Load and Deliberate Practice." Educ. Technology, Research and Develop., vol. 53, no. 3, pp. 73-81, 2005. https://doi.org/10.1007/BF02504799

[15] S.W. Bonham, D.L. Deardorff and R.J. Beichner, "Comparison of Student Performance Using Web and Paper-Based Homework in College-Level Physics." J. of Research in Sci. Teaching, vol. 40, no. 10, pp. 1050-1071, 2003. https://doi.org/10.1002/tea.10120

[16] D.S. Brewer and K. Becker, "Online Homework Effectiveness for Underprepared and Repeating College Algebra Students." J. of Comput. in Math. and Sci. Teaching, vol. 29, no. 4, pp. 353-371, 2010.

[17] L. Lenz, "The Effect of a Web-Based Homework System on Student Outcomes in a FirstYear Mathematics Course." J. of Comput. in Math. and Sci. Teaching, vol. 29, no. 3, pp. 233-246, 2010.

[18] E. Mathai and D. Olsen, "Studying the Effectiveness of Online Homework for Different Skill Levels in a College Algebra Course." PRIMUS: Problems, Resources, and Issues in Math. Undergraduate Stud., vol. 23, no. 8, pp. 671-682, 2013. 
[19] P. Babaali and L. Gonzales, "A quantitative analysis of the relationship between an online homework and student achievement in pre-calculus," Int. J. of Math. Educ. in Sci. and Technology, vol. 46, no. 5, pp. 687-699, 2015. https://doi.org/10.1080/0020739X .2014 .997318

[20] T. Wooten and J. Dillard-Eggers, "An Investigation Of Online Homework: Required Or Not Required." Contemporary Issues In Educ. Research, vol. 6 , no. 2, pp. 189-198, 2013. https://doi.org/10.19030/cier.v6i2.7728

[21] R. Zerr, "A quantitative and qualitative analysis of the effectiveness of online homework in first-semester calculus." J. of Comput. in Math. and Sci. Teaching, vol. 26, no. 1, pp. 5573, 2007.

[22] A. Hodge et al.,"The Impact of a Web-based Homework Tool in University Algebra Courses on Student Learning and Strategies." Merlot J. of Online Learning and Teaching, vol. 5, no. 4, pp. 618-629, 2009.

[23] K.E. Leong and N. Alexander, "College Students Attitude and Mathematics Achievement Using Web Based Homework.” Eurasia J. of Math., Sci. \& Technology Educ., vol. 10, no. 6, pp. 609-615, 2014.

[24] D. Macnab, H.D. Mickasch and W. Georgi, "Description and assessment of different methods of teaching engineering students mathematics." Int. J. of Math. Educ. in Sci. and Technology, vol. 8, no. 2, pp. 219-228, 1977. https://doi.org/10.1080/0020739770080210

[25] C. Sangwin, Computer Aided Assessment of Mathematics. Oxford: Oxford University Press, 2013. https://doi.org/10.1093/acprof:oso/9780199660353.001.0001

\section{Authors}

Mikko Vasko, M.A., works in Projekt SKATING at the Karlsruhe University of Applied Sciences, Moltkestr. 30, 76137 Karlsruhe, Germany.

Stefan Ritter, Prof. Dr. rer. nat., is professor for engineering mathematics at the Faculty of Electrical Engineering and Information Technology at the Karlsruhe University of Applied Sciences, Moltkestr. 30, 76137 Karlsruhe, Germany.

Gottfried Metzger, Dipl.-Psych., works in Projekt SKATING at the Karlsruhe University of Applied Sciences, Moltkestr. 30, 76137 Karlsruhe, Germany.

Article submitted 03 August 2017. Resubmitted 03 November 2017. Final acceptance 05 February 208. Final version published as submitted by the authors.. 